\title{
Consumers' Satisfaction Regarding Fast food Restaurants
}

\author{
Andreea Cipriana Muntean ${ }^{1}$ Pastiu Carmen ${ }^{2}$
}

\begin{abstract}
:
In recent years there has been a significant increase in the number of fast food restaurants. An important aspect of the global and national success of these companies can be ascribed to the consumers' satisfaction regarding the products they offer, while media promotes the negative effects on the health of individuals. Satisfied consumers will repeatedly buy the respective products and will also recommend them to others; for the company this is reflected in economic and social efficiency. The government, consumers and other entities play a significant role in ensuring food quality and safety. The purpose of the research is to identify the attributes of fast food products and restaurants that contribute to consumers' satisfaction regarding the products and services offered by them.
\end{abstract}

Key Words: Consumer Satisfaction, Fast Food Industry, Food Safety, Quality

JEL Classification: M3, L80, L83

1 "1 Decembrie 1918" University of Alba Iulia, Nicolae Iorga Street, no. 11-13, Alba Iulia, Alba County, Romania, e-mail: munteanandreea2009@yahoo.com

2 "1 Decembrie 1918" University of Alba Iulia, Nicolae Iorga Street, no. 11-13, Alba Iulia, Alba County, Romania, e-mail: carmenpastiu@yahoo.com 


\section{Introduction}

Consumers have the right to expect the food they buy to have an appropriate quality and to be safe. In ensuring food safety standards, the organizations involved must be sure that all consumers will receive the same level of protection, that all producers (local or foreign) will apply the safety standards in the same way, and that all consumers will be informed about the existence and application of these standards. In their purchasing decisions, besides other factors, consumers are also influenced by variables related to marketing communication. In the messages transmitted to them by different organizations should be highlighted aspects regarding the availability, the consumption manner and the benefits of consuming different food products. The role of labeling should not be neglected; the information appearing on the label will help consumers to make rational decisions.

In the food industry, the control of food is subject to some factors such as:

Safety, namely establishing the standards of the toxicological and microbiological content and setting up some procedures regarding the certification of the way in which these procedures are followed:

- Nutritional value, which implies the addition of some ingredients meant to ensure a balanced diet for the consumer;

- Quality, given by characteristics such as taste, flavor, appearance;

- Value, which refers to the utility and economic advantage of the product for the consumer (convenience, affordability, packaging, etc.).

- Various studies published in the scholarly literature demonstrate the negative effects of fast food consumption on our health. Among them we can find the ones mentioned below:

- Migraines - caused mainly by the content of nitrates, nitrites or artificial sweeteners that cause an increase in blood pressure. These additives are used in order to preserve fresh meat and prevent the development of a bacteria (Clostridium botulinum);

- High cholesterol level - the processed foods used in the fast food industry lead to high blood cholesterol levels and these, in turn, lead to heart problems;

- Depression - is one of the most common negative effects caused by fast food consumption. According to a study by University College of London, those who regularly consume such products have a $58 \%$ increased risk to suffer from depression compared with those who never eat or eat very rarely;

- The salt retention in the body - is favored by the high salt content of these products and can lead to high blood pressure or hypertension.

- Food poisoning - caused by the possibility that the contaminated meat contains E. coli and Salmonella. Although the bacteria can be destroyed by 
antibiotics, the toxins that are released can cause serious diseases such as kidney failure;

- Obesity - numerous studies have shown a direct link between fast food consumption and weight gain (Body Mass Index). In turn obesity causes diabetes, heart problems, high cholesterol, etc. In the United States of America this is considered to be one of the most serious health problem of its inhabitants.

A part of these factors represent solely the concern of consumers and of industry organizations (such as value) and others of the government, but also the consumers and companies in the industry.

Quality assurance programs focus on the "hazard analysis" technique and the critical control point technique, given the expanding of the fast food industry in the last two decades. The elements covered by these programs are: using the "hazard analzysis" in order to identify the evidence, establishing the critical control points, establishing critical limits for each control point, establishing the monitoring procedures, and also the corrective actions, the control procedures, as well as the documentation necessary to conduct the audit of the control.

The fast food industry emerged in the United States, where there are currently over 2 million people working in this field. The data show that one third of American children eat fast food products on a daily basis. Even in India, the industry grew tremendously - by $46 \%$ - a few years ago, especially due to the expansion of McDonald's and KFC chains.

According to an article published in 2009 by the Financial Newspaper, over 250.000 Romanians buy fast-food products daily only from McDonald's and KFC chains. It is appreciated that fast-food alimentation is responsible for diseases such as obesity, diabetes, heart diseases, etc. Hamburgers, cheeseburgers, French fries, and other similar products contain very few nutrients and thereby harm the health of young people and children who are among the most common consumers.

In 2010, the Romanian government has tried a legislative proposal aimed at introducing a tax on fast food products in order to encourage a healthy diet. The initiative failed when it was found that many fast food products could not be classified as "junk food". Kebabs, for example, according to the sellers' statements, could not be included in the "junk food" category just because it was prepared quickly. It contains fresh ingredients, except the mayonnaise. The bill did not materialize, instead the government demanded that a list of over 40,000 products considered unhealthy to be drafted.

\section{Consumer Satisfaction}

Consumer satisfaction is vital to the success of a business because it has been demonstrated that it is closely related to the repurchase, loyalty and profitability. Satisfied consumers are believed to manifest a higher probability to buy the 
respective product or service again. Dissatisfied consumers show their resentment towards the business, file complaints, demand back the money paid for the product and even influence other buyers in a negative way.

Consumer satisfaction had been typically conceptualized both as an emotional and cognitive response. The latest definitions of satisfaction consider it an emotional response whose intensity varies depending on the situation. Despite numerous researches conducted over the years, beginning with the first attempt to define consumer satisfaction in 1965 belonging to Cardozo, a consensus regarding the definition of this concept has not yet been reached. In 1997, Oliver - a renowned researcher in the field - stated that "everyone knows what satisfaction is until he is required to define it. And then, nobody knows."

Starting from the idea that satisfaction has been defined, most researches were concerned with testing models of consumer satisfaction (Mano and Oliver in 1993, Oliver and DeSarbo in 1988, Tse and Wilton in 1988), while the aspects concerning the definition of the concept had been given less attention. For this reason, there are many conceptual and operational definitions of consumer satisfaction in the specialty literature.

One of the causes behind the inconsistency concerning the definition of the concept refers to the disagreement of opinions with regard to considering satisfaction as a process or a benefit. Thus, some authors such as Fornell (1992), Hunt (1977), Oliver (1981) have defined satisfaction as an evaluation process while others, such as Howard and Sheth (1969), Tse and Wilton (1988), Westbrook and Reilly (1983) have defined this concept as being a response to an evaluation process. From a general perspective, the definitions approaching satisfaction as a process are problematic due to their lack of consistency. From an operational perspective, these definitions include too much history of the concept and so, there is an overlap between satisfaction determinants and the concept itself.

Most definitions, however, considered consumer satisfaction as a response to an evolution process. Therefore, satisfaction was appreciated as being an emotional response (Halstead, Hartman and Schmidt in 1994), a general evaluation (Fornell in 1992), a psychological state (Howard and Sheth in 1969), a global evaluative judgment (Westbrook in 1987) or an evaluative response (Day in 1984).

There is also a disagreement in the nature of this concept. Some researchers consider satisfaction as being a cognitive response (Bolton and Drew in 1991, Howard and Sheth in 1969, Tse and Wilton in 1988) and others as an emotional response (Cadotte, Woodruff and Jenkins in 1987, Westbrook and Reilly in 1983). Moreover, there are situations in which operational definitions include behavioral dimensions of 
satisfaction although these conceptual definitions should avoid behavioral guidelines.

Another discrepancy is seen in regard to the term used to describe this concept. Therefore, terms such as consumer satisfaction (Cronin and Taylor in 1992, Oliver in 1993, Tse and Wilton in 1988, Westbrook in 1980), client satisfaction (Churchill and Surprenant in 1982, Fornell in 1992) or simply satisfaction (Oliver in 1992, Oliver and Swan in 1989) were used.

\section{Research Methodology}

The research method consisted in a Focus Group conducted among students from " 1 Decembrie 1918" University of Alba Iulia, within which were used different projective methods (thematic apperception test, the free association technique). The objectives of the research were, on the one hand, to identify the criteria considered by them when they declare themselves satisfied with the products offered by fast food restaurants, the motivation for purchase and on the other hand to identify to what extent they are aware of the adverse health effects.

The interview guide that was used included several discussion topics set according to the research objectives, namely: (1) To what extent do young people consume fast food, (2) The circumstances in which they consume fast food and how frequently, (3) Why are they satisfied with the restaurants and the fast food (4) If they are aware of the harmful effects on their health.

The participants were recruited from among young people aged between 18 and 23, students of the "1 December 1918" University of Alba Iulia, which consumed fast food products in the last month and did not participate in last 6 months in a focus group. An important condition was that participants had not previously known each other.

The research was conducted over half an hour, the discussion was moderated by the author of the paper and recorded with audio-video equipment, and the participants were guaranteed anonymity and confidentiality of the collected data.

\section{Results}

A general problem was addressed in the opening of the discussion, the moderator bringing into question the significance of what it means to be healthy. From statements such as "being healthy means having physical strength", "being healthy means not getting tired quickly," "being healthy means to have a normal weight and to be able to sustain intellectual effort", we can draw the conclusion that young people are concerned about their health. In the opinion of many, there is a direct link 
between an individual's nutrition and his or her health: "food should not only give you a feeling of satiety, but also vitamins and other essential nutrients."

In the next part of the discussion, the participants were asked to say what they mean by and what they include in the category of fast food. According to the answers given by some of them, these products "are prepared very quickly and contain an enormous amount of fat," and in this category they include hamburgers, cheeseburgers, French fries and pizza - if frozen. The cooking time and the ingredients used are the main criteria considered in classifying of products as fast food.

Among the identified consumption motivations we found some such as: taste ("products taste delicious"), the low price compared to other meals, lack of time for cooking ("I eat them when I have no time to cook", "eating fast food is an advantage when you have no time to cook ") or as a meal taken in the city ("when I'm out in the city and I'm hungry"). One of the participants argued that a possible reason for the excessive consumption of these products can be the result of various psychosocial problems of young people and the excessive use of the computer for socializing or gaming, gambling etc.

Among their favorite restaurants they included McDonald's, which two of the investigated people said they visited whenever they had the opportunity - in a city other than Alba Iulia. Also "the enticing smell" may be an important factor in choosing a fast food restaurant for dining.

These kinds of products are not consumed at home, but only in the city, as a quick alternative to the main meal of the day. Some of the investigated subjects claimed that fruit or yogurt are not a "consistent" alternative of the main meals (breakfast, lunch or dinner), but rather a snack. Although the participants occasionally consumed fast food products, they proved to be aware of the harmful effects on health. In this regard, they underlined the growing number of obese children in Romania and they are aware of the health problems that can be caused by obesity, such as diabetes and depression.

In the last part of the Focus Group, the moderator applied the projective technique known as the Thematic Apperception Test. The investigated subjects were presented with an image showing two young girls on their lunch break. One of them eating a hamburger purchased from a well known fast food restaurant, and the other one offering her a piece of fruit. The participants were asked to say what they thought to be the response of the young girl. The most frequently given answer was "first I will eat the hamburger and then the apple". As a conclusion of the discussion, the moderator conducted a brief summary. 


\section{Conclusion}

The obtained results, without any claim to be generalized, lead to conclusions that can be subsequently used to organize a conclusive quantitative research among Romanian young people, regarding the fast food consumption motivations and the association between that and the level of awareness concerning the harmful effects on their health.

Although they are aware of the consequences that may arise from the consumption of such products, young people are satisfied with the fast food products. The most frequently mentioned attributes that are essential in forming their satisfaction are: short cooking time, consistency, taste, ambiance of the restaurant, service, price quality ratio.

We can conclude from the research that the investigated young people are aware of the negative consequences that can arise from eating fast food and what's more - they get information from various available sources (Internet, themed TV shows, and magazines) on what healthy eating means. This implies the need for continuous information among young people.

\section{References}

Codex Alimentarius Commission, Code of ethics for international trade in food, CAC/RCP 20-1979, Rev. 1 (1985), Rome, FAO/WHO, 1987

Cătoiu I. (Coordinator), Cercetări de marketing - Treaty, Uranus Publishing House, Bucharest, 2009

Cătoiu, I., Teodorescu, N., Comportamentul consumatorului, ediţia a II-a, Editura Uranus, Bucureşti, 2004

FAO/WHO, Report of the FAO/WHO Conference on Food Standards, Chemicals in Food and Food Trade, Rome, 1991

Fiona McCullough, Sian Jones, Daniella Vignali, The pot snack market - are today's consumers demanding health as well as convenience?, British Food Journal, Vol. 105 Iss: 6, pp.395 - 404, 2003

Giese, J.L., Cote, J.A., Defining Consumer Satisfaction, Academy of Marketing Science Review, vol. 1, 2002

Grocery Manufacturers of America, Guidelines for product recall, Washington, DC, 1983

Hayes, B.E., Measuring Customer Satisfaction - Survey Design, Use and Statistical Analysis Methods, ASQ Quality Press, Wisconsin, 1997

Hotchkiss, J.H., Pesticide residue controls to ensure food safety. Critical Reviews in Food Science and Nutrition. 31(3); 191-203, 1992

Ippolito, P.M. \& Mathios, A.D., Health claims in labelling and advertising, a study of the cereal market. Washington, DC, United States Federal Trade Commission, 1989

Jay, J.M., Microbiological food safety, Critical Reviews in Food Science and Nutrition, 31 (3): 177-190, 1992 
Labuza, T.P, Basier, W., The role of the Federal Government in food safety. Critical Reviews in Food Science and Nutrition, 31 (3): 165-176, 1992

Moonkyu Lee, Francis M. Ulgado, Consumer evaluations of fast-food services: a crossnational comparison, Journal of Services Marketing, Vol. 11 Iss: 1, pp.39 - 52, 1997

Oliver, R., Satisfaction: A Behavioral Perspective on the Consumer, The McGraw-Hill Companies, Inc. New York, 1997

Pillsbury Company. Development of a food quality assurance programme and the training of FDA personnel in hazard analysis techniques. Minneapolis, Minnesota, USA, 1973

United States Food and Drug Administration, Current good manufacturing practice in manufacturing, packing or holding food. 21 CFR, Part 110. Washington, DC, 1992

Yi,Y., A Critical Review Of Consumer Satisfaction, Review of Marketing, American Marketing Association, Chicago, 1990; 